\title{
Making Roundness Measurement Applications and Control Systems on the Roundness Tester Machine
}

\author{
Dodi Sofyan Arief, ${ }^{\text {a, }}$ Eko Jadmiko, ${ }^{\text {a }}$ Adhy Prayitno, ${ }^{a}$ Muftil Badri, ${ }^{a}$ and M. Dalil, ${ }^{\mathrm{a}}$ \\ a) Mechanical Engineering Department, Universitas Riau, Indonesia \\ *Corresponding author: dodidarul@yahoo.com
}

\section{Paper History}

Received: 30-September-2019

Received in revised form: 25-November-2019

Accepted: 30-November-2019

\begin{abstract}
Dial indicator is a comparison device usually used in industrial activities, especially in production. To make measurements at this time must be supported by technology that can facilitate operators when using it and when analyzing measurement results. Involving the programmed and microcontroller are a solution to developing in roundness measurement, and then the results can be more accurate or thorough between the readable values read from the measuring instrument with the actual value of varying the amount of data. Roundness application is a program that can input measurement data automatically and can do calculations directly. Then, it can display a reference circle, a table that calculates the values of X, Y, R, X', Y', R', Roundness Deviation, Run out Concentricity or a shift in the center point and also the center point shift or Theta. In measuring roundness, the test object is used the Standard Mandrel which has been certified by PT. Global Quality Indonesia, by determining three points or positions, namely in the first position the amount of data is 180 , in the second position the amount of data is 90 and in the third position the amount of data is 60 with a rotating speed of 15 $\mathrm{mm} / \mathrm{s}$. The results of the reference circle can be seen in each calculation in each position, in the second position the roundness deviation values are approaching of the Mandrel.
\end{abstract}

KEY WORDS: Roundness application, position, measurement, data variation.

\subsection{INTRODUCTION}

Roundness has an important role in terms of dividing the load equally, determining the life of components, determining the conditions of the suit, determining the accuracy of the rotation, smoothing lubrication in producing the desired product, especially products that are round [1].

Roundness is the uniformity of the distance between the center point and the outermost point (radius). Roundness measurement is a measurement that is shown to check the roundness of an object, or in other words to find out whether an object is really round or not, if viewed carefully with a measuring instrument [2].

To be able to express the level of roundness of a measuring object, it is necessary to establish a roundness parameter. Roundness parameters can be calculated based on the roundness profile, relative to the reference circle. In this case, four types of reference circles can be used in determining the value of roundness parameters.

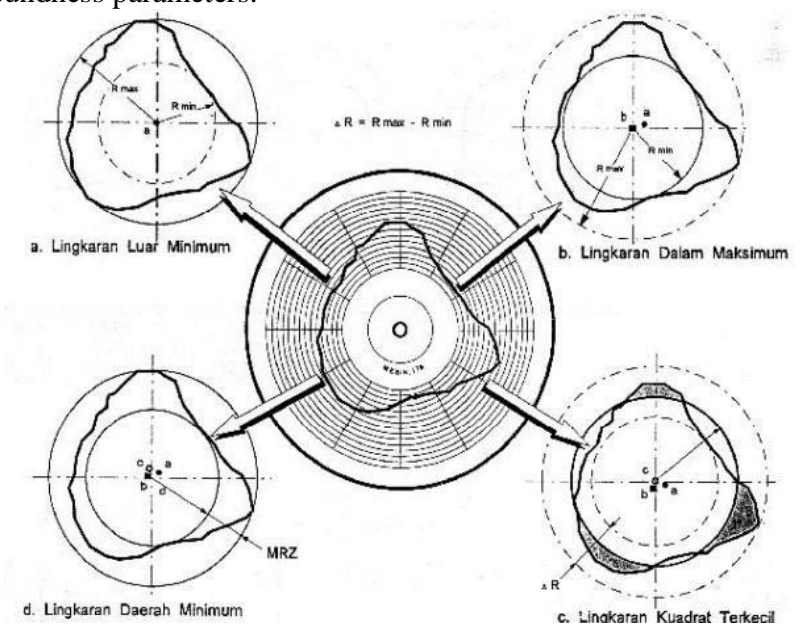

Figure 1: Polar graph of four types of reference circles. 
a. Minimum circumscribed circle

Non-rotation is the same as the radial distance from the circle to the deepest curve.

b. Maximum inscribed circle

The roundness is equal to the radial distance from the circle to the highest protrusion.

c. Minimum zone circle

Inaction is the difference in the radius of the two circles.

d. Least square circle

The radial distance of the absolute average price between the roundness profile and the smallest square circle is called the mean line average (MLA)

According to JIS (B0651-1984), "Roundness is defined as the sum of the deviations in the shape of a circle from a definite geometric circle." Here the shape of a circle is a form that is specified to be a circle as a shape of a field or cross-section of a surface that rotates [3].

Components with ideal roundness are very difficult to make, and thus must be tolerated by non-roundness within the boundaries of the point according to the purpose and function of the component. Roundness has an important role in terms of dividing the load equally, determining the life of components, determining the conditions of the suit, determining the accuracy of the rotation, smoothing lubrication [4], in producing the desired product, especially cylindrical products.

To determine the accuracy of the measuring instrument and measurement results, of course, there must be a basic reference that is used as a clear reference to the source. A mandrel is a standard measuring instrument that has been calibrated and certified for roundness quality by a calibration institution, namely PT. Global Quality Indonesia; this data will be used as a basic reference to determine the accuracy of making roundness applications [5].

Roundness can be measured in a simple way using the Dial Indicator, but currently, it is still difficult to determine the roundness so a program can be analyzed directly on a computer (PC), and the roundness program is currently still difficult to obtain because the program has a price selling high in the market. Roundness programs are usually sold separately from the measuring instrument with the program. So we need an application that can determine the price of roundness.

Based on the description above, the authors aim to conduct research that can later analyze the measurement of roundness (roundness) to declare the price of roundness by using roundness parameters so that it makes it easier for operators to make roundness measurements.

\subsection{METHODOLOGY}

\subsection{Research Flow}

The composition of the research will be conducted:

1. Analyze the existing roundness measurement data management system manually as a Literature Study.

2. Designing a measurement system and processing data measurement results automatically.

3. Creating an Automatic Control System and roundness measurement data processing software on the Roundness Tester Machine.
4. Calibrate the Roundness Tester Machine with a certified Standardized Roundness (Mandrel).

5. Test the Roundness Tester Machine with two methods, namely the Point and Curve method.

6. Analyzing the results of data processing from software that displays a polar graph of the reference circle, the results of the calculation of the value of $\mathrm{X}, \mathrm{Y}, \mathrm{R}, \mathrm{X}$ ', Y', R ', Roundness Irregularities, Runout, Concentricity or the shifting of the center point and also the magnitude of the point shift center or Theta.

\subsection{Research Approach}

Research conducted using methods consisting of needs analysis and system modeling such as material/research data, analysis and design approaches; application software modeling; implementation and testing of application systems. Next, the flow methodology for rounding data processing applications in the Roundness Tester Machine is shown in Figure 2.

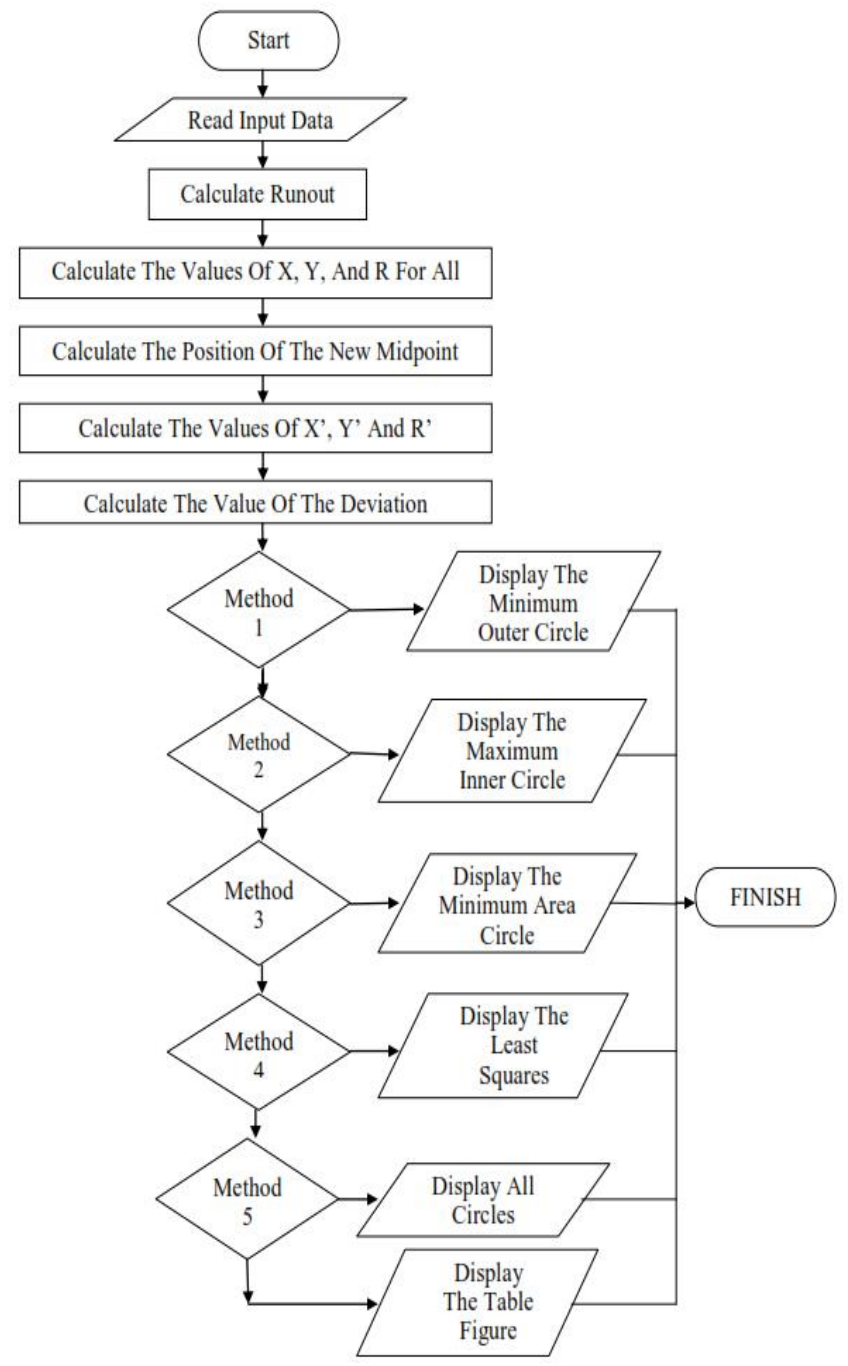

Figure 2: Flowchart application development stages. 


\subsection{RESULTS AND DISCUSSION}

This research was conducted with the aim of producing a more accurate or accurate roundness measurement data processing system between the value read from the measuring instrument and the actual value on the Roundness Tester Machine.

This research activity resulted in a prototype of a Roundness Tester Machine with a method of measuring the between center method, where the clamping of the test object (Mandrel) was carried out on the right and left sides of the test object. Measuring devices are made automatically in the movement of rotating test specimens and the movement of indicators in measuring roundness results, is shown in Figure 3.

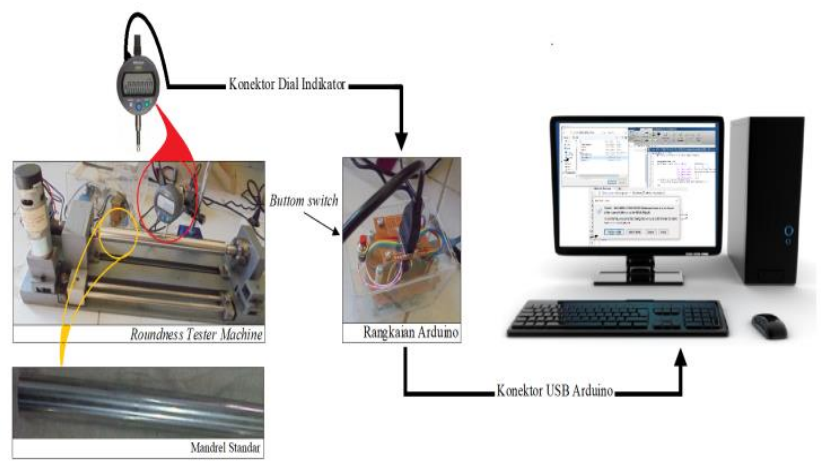

Figure 3: A series of research tools.

\subsection{Rounding data input using Dial Indicator (Microcontroller)}

The process that is carried out to carry out this data uses a Digital Dial Indicator with the accuracy of 0.001 connected by a connector to the microcontroller circuit (Arduino) and connected directly to a PC or Laptop, as for the shape of the circuit and its stages can be seen in Figure 3.

The test object (Mandrel) is gripped on two flashlights on the Roundness Tester Machine and the Digital Indicator Dial that is connected by Arduino is positioned above the test object (Mandrel) and reset the Digital Dial Indicator until it shows the number on the monitor 0,000. Open the Arduino application and run the program, then set on the Arduino program the amount of data and time of the shaft rotational speed (rpm), then click Upload and select Serial Monitor, to see the process of data entering the program can be seen in Figure 4.

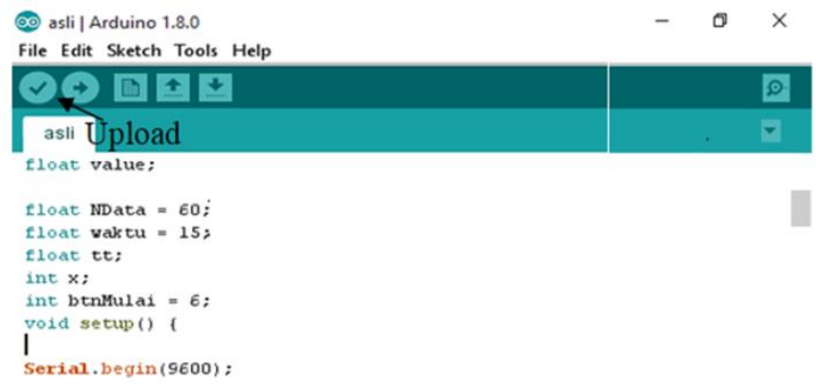

Figure 4: Data and Time Management for Arduino.

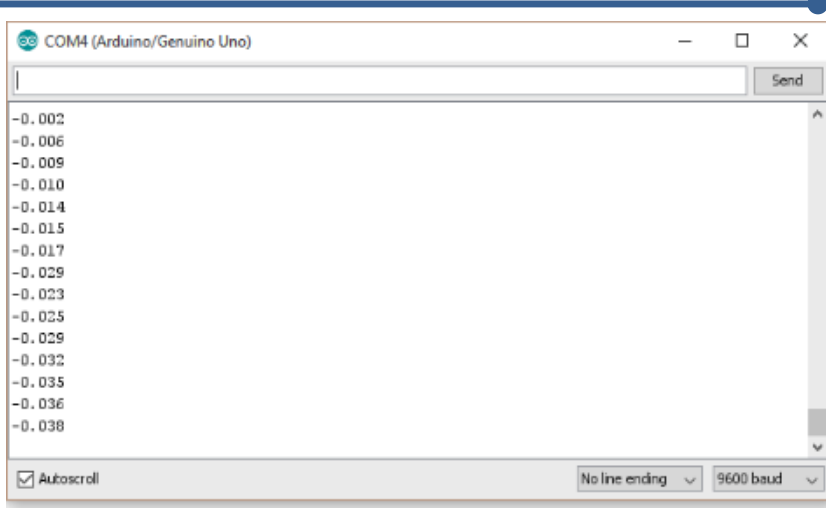

Figure 5: Data Collection Process in Arduino.

The Roundness Tester Machine is turned on, then in the Arduino circuit press the button to start capturing data automatically. Retrieval of data will stop with the amount of data and time that has been determined, the process of incoming data in the Arduino application can be seen in Figure 5.

\subsection{Rounding data processing with roundness application (MATLAB)}

This roundness application is made by using the MATLAB program after data retrieval is done using Arduino then the data copied to the Excel program is positioned in column B, for pool $\mathrm{A}$ is given a number of data numbers. The data obtained is added to the value of the test object diameter (Mandrel) can be seen in Figure 6, in this test the diameter of the Mandrel is $25 \mathrm{~mm}$.

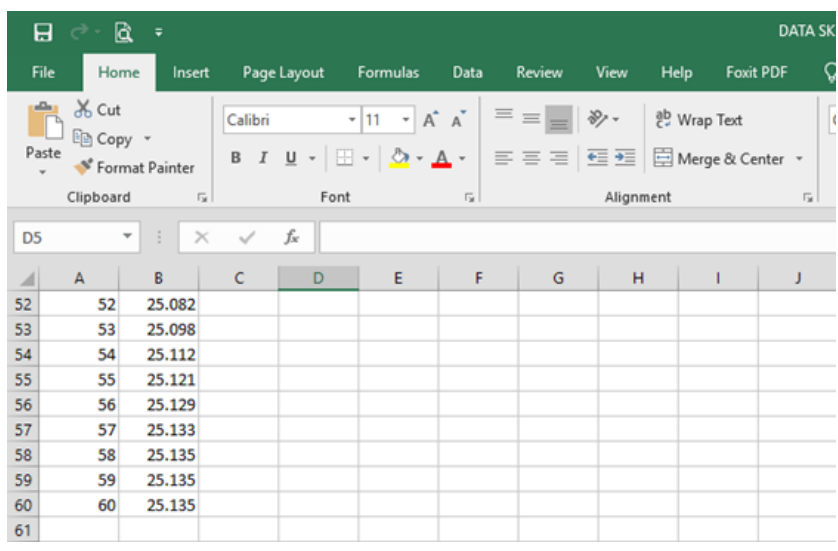

Figure 6: Data Addition Stages with Diameter of Test Objects (Mandrel).

Save in the Data Processing Applications folder Roundness, open the MATLAB program, click the Open menu, find the storage location of the Roundness Applications folder and select the file Home First.m, select the menu click RUN then the comment will appear, select the comment Change Folder will open the Roundness Application, then do roundness data processing using the Roundness application, can be seen in figure 7. 


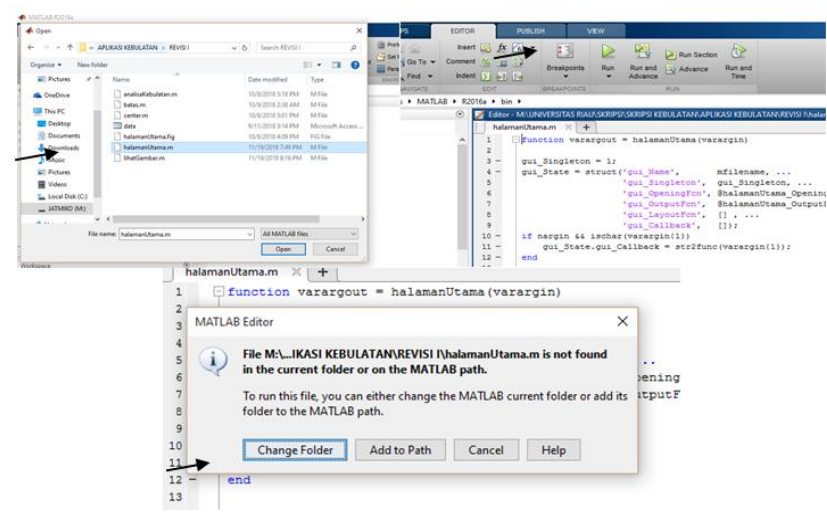

Figure 7: Command to Run a Roundness Application.

Rounding data processing can be done by entering data in the Roundness Data Processing Application with the Open File menu and then selecting the data to be calculated (Data 180.90 and 60) in the folder that has been saved in the Excel program that can be seen in Figure 8.

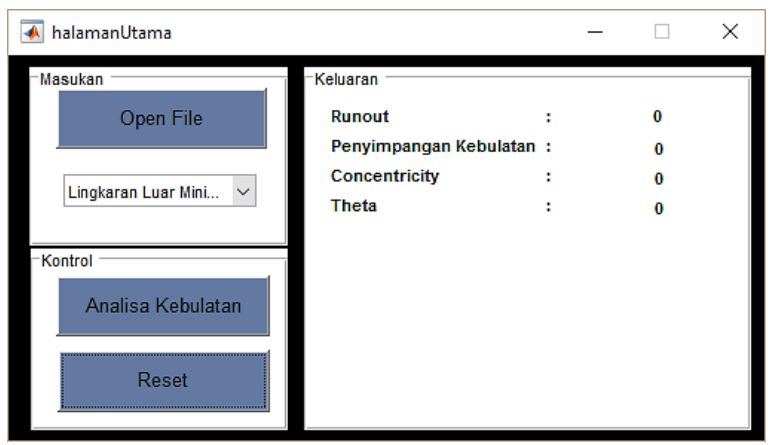

Figure 8: Roundness Data Processing Application.

In the reference circle selection menu there are 5 choices, namely the Minimum Outer Circle, Maximum Inner Circle, Minimum Area Circle, Squared Circle, and All References. Select one, and then select the Roundness Analysis menu, then roundness data will be obtained such as Runout, Roundness Deviation, Concentricity and Theta. It can be seen in Figure 9.

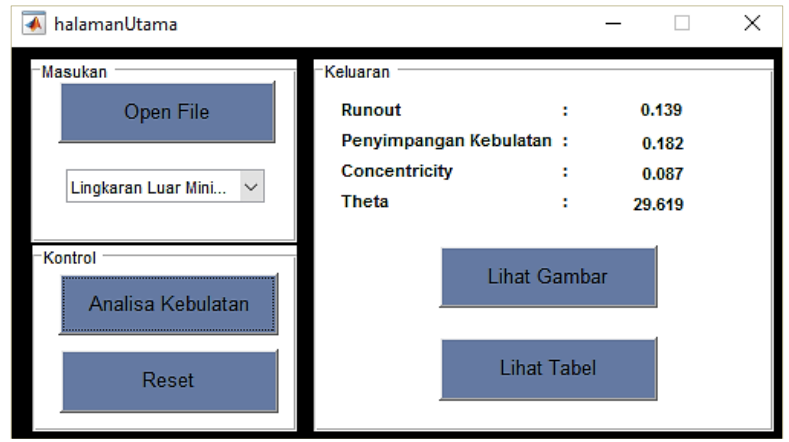

Figure 9: Calculation Results.
On the View this Figure menu to display the desired circle of references and on the View Table menu it is to display tables of the calculation results of the values of $\mathrm{X}, \mathrm{Y}, \mathrm{R}, \mathrm{Y}^{\prime}, \mathrm{X}^{\prime}$ and $\mathrm{R}^{\prime}$ simultaneously in one table, can be seen in Figure 4.1. Display See this table to copy moved first to the Excel program by copy and paste. To calculate the next data or other roundness data, first, select the Reset menu and re-enter the data to be calculated in the manner described.

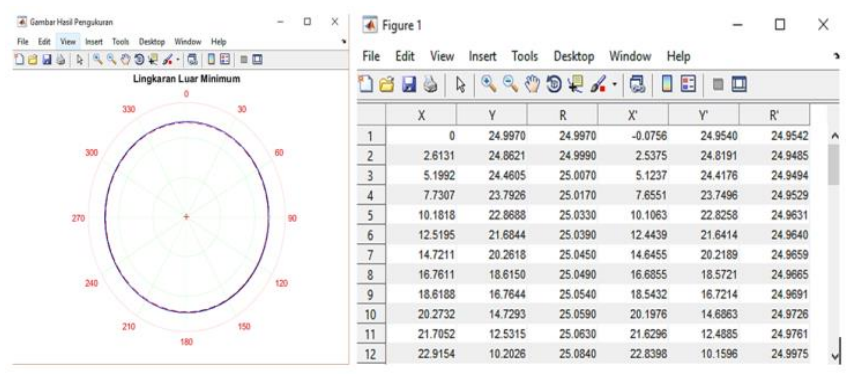

Figure 10: Display Menu See Figure and See Table.

\subsection{CONCLUSIONS}

The conclusions that can be obtained based on calculations and analysis of the application of roundness (Roundness) with variations of data, the causes of roundness irregularities, as follows:

1. This Roundness Data Processing application greatly facilitates operators in taking data on roundness measurements because data retrieval operations are done automatically, the amount of data to be cooled can be determined directly, this data processing can be done simultaneously and displays a reference circle and table of results calculation of the value of $\mathrm{X}, \mathrm{Y}, \mathrm{R}, \mathrm{Y}^{\prime}, \mathrm{X}^{\prime}$ and $\mathrm{R}^{\prime}$, making it easier to analyze the results of the test.

2. Calculation results from three variations of the amount of data used 180 data, 90 data, and 60 data with a rotation speed of 15 $\mathrm{mm} / \mathrm{s}$ values close to the Mandrel are on data 180, with a roundness value of $0.061 \mathrm{~mm}$ with a central point displacement (Concentricity) of $0.008 \mathrm{~mm}$ and shrinkage of Theta $-33,962^{\circ}$, based on the Minimum Outer Circle, the Maximum Inner Circle, the Drinking Area Circle, and the Smallest Circle clearly illustrated, the roundness can be stated.

3. The application of Roundness is very well applied for measurement of roundness in the Laboratory of Measurement Engineering at the University of Riau, because it can provide enrichment to the practitioner with the support of its youthful way of operation, and balance the measurement with increasingly rapid technological development.

\section{ACKNOWLEDGEMENTS}

The authors sincerely acknowledge the Research and Community Service Institute of Universitas Riau which supported this research by Penelitian Dosen Muda program in 2019, contract no. 24/UN.19.5.1.3/PT.01.03/2019. 


\section{REFERENCE}

1. Taufiq, R. (2001). Spesifikasi, Metrologi \& Kontrol Kualitas Geometrik 1. Bandung: ITB.

2. Taufiq, R. (2006). Spesifikasi, Metrologi \& Kontrol Kualitas Geometrik 2. Bandung: ITB.

3. Hamdi, E., Arief, D.S. and Prayitno, A. (2015). Pengujian Kebulatan Hasil Pembuatan Poros Aluminium Menggunakan Emco T.U CNC-2a Smkn2 Pekanbaru Dengan Roundness Tester Machine. Jurnal JOM FTEKNIK, 2(2).

4. JIS B0651-1984.

5. Shodikin, Arief, D.S. and Prayitno, A. (2015). Studi Kecermatan Alat Ukur Roudnees Tester Machine Produksi Laboratorium Jurusan Teknik Mesin Universitas Riau Dengan Metode Helix. Jurnal JOM FTEKNIK, 2(2).

6. Nemedi, Imre., Sekulić, Milenko and Radlovački, V. (2017). A Method for Determining Roundness and Actual Form of Circular Workpiece Cross Sections. Jurnal of Acta Polytechnica Hungarica, 14( 6).

7. Parma, I., Paryitno, A. and Arief, D.S. (2015). Studi Kecermatan Alat Ukur Kebulatan (Roundness Tester Machine) Produksi Laboratorium Pengukuran Universitas Riau. Skripsi. Fakultas Teknik Universitas Riau. 